\title{
Impact of COVID-19 Pandemic on Zomato: A Case Study
}

\author{
K. M. Kiran Raj ${ }^{1,2}$ \& K. G. Nandha Kumar ${ }^{3}$ \\ ${ }^{1}$ Research Scholar, College of Computer Science and Information Science, Srinivas \\ University, India \\ ${ }^{2}$ Lecturer, Department of Computer Applications, Sri Venkataramana Swamy College, India \\ OrcidID: 0000-0002-7057-7951; Email: kiranraj224@gmail.com \\ ${ }^{3}$ Associate Professor, College of Engineering and Technology, Srinivas University, India \\ OrcidID: 0000-0002-5716-7122; Email: professorkgn@gmail.com
}

Area of the Paper: Information Technology.

Type of the Paper: Research Case Study.

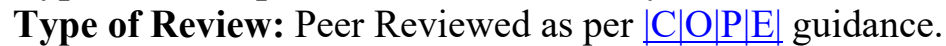

Indexed In: OpenAIRE.

DOI: $\underline{\text { http://doi.org/10.5281/zenodo.4492571 }}$

Google Scholar Citation: IJCSBE.

\section{How to Cite this Paper:}

Kiran Raj, K. M., \& Nandha Kumar, K. G., (2020). Impact of COVID-19 Pandemic on Zomato: A Case Study. International Journal of Case Studies in Business, IT, and Education (IJCSBE), 5(1), 14-24. DOI: https://doi.org/10.5281/zenodo.4492571

International Journal of Case Studies in Business, IT and Education (IJCSBE)

A Refereed International Journal of Srinivas University, India.

(C) With Authors.

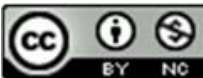

This work is licensed under a Creative Commons Attribution Non-Commercial 4.0 International License subject to proper citation to the publication source of the work.

Disclaimer: The scholarly papers as reviewed and published by the Srinivas Publications (S.P.), India are the views and opinions of their respective authors and are not the views or opinions of the S.P. The S.P. disclaims of any harm or loss caused due to the published content to any party. 


\title{
Impact of COVID-19 Pandemic on Zomato: A Case Study
}

\author{
K. M. Kiran Raj ${ }^{1,2}$ \& K. G. Nandha Kumar ${ }^{3}$ \\ ${ }^{1}$ Research Scholar, College of Computer Science and Information Science, Srinivas \\ University, India \\ ${ }^{2}$ Lecturer, Department of Computer Applications, Sri Venkataramana Swamy College, India \\ OrcidID: 0000-0002-7057-7951; Email: kiranraj224@gmail.com \\ ${ }^{3}$ Associate Professor, College of Engineering and Technology, Srinivas University, India \\ OrcidID: 0000-0002-5716-7122; Email: professorkgn@gmail.com
}

\begin{abstract}
The advancement and use of smart-phones and internet resulted in improving online services. Zomato is a digital platform combining restaurants and an online food delivery system launched in 2008. The implementation of Lockdown to slow down the spread of pandemic COVID-19 resulted in badly affecting tourism, transport, economy, and hotel industry. Zomato food delivery is recovering from the effect of COVID-19 at a rapid rate with $\sim 80 \%$ recovery in metro regions. The revenue in the fiscal year 2020 is increased by $105 \%$ and cost by $47 \%$. The main objective of this paper is to understand online food delivery service by using a survey, how Zomato is operating in COVID-19, its effect on the culture of the hotel industry, the introduction of contactless dinning and challenges. The evaluation of the company is done using the SWOT analysis.
\end{abstract}

Keywords: Zomato, Food delivery, Dining out, Contactless dining, SWOT analysis

\section{INTRODUCTION:}

The boom in e-commerce is directly influenced online delivery service. The most influential tool today is social media. The integration of multiple social media channels such as Facebook, Instagram, Twitter, to support everything and anything to draw an increasing number of buyers. Food delivery services as a company has grown in prominence along with technical advances. The way the food industry works and does business has been instrumental in improving it. Since products/foods are delivered with discounts and exclusive deals, clients find like they can save even more by online applications.

Zomato is online food delivery company bringing restaurant and customer together, which not only delivers food but also provides information about restaurants, menu and user review. Currently operating in 24 countries and selected $10000+$ cities serving 100 million+ customers. Founded by Deepinder Goyal and Pankaj Chaddah [1]. Started in $26^{\text {th }}$ January 2008 as foodlet.in in Delhi provided information regarding menu of restaurants. Renamed as foodiebay.com in $10^{\text {th }} \mathrm{July} 2008$. on $8^{\text {th }}$ January 2010 started providing online food delivery services along with previous information and renamed itself as Zomato. From 2011 it moved to other metro cities and to other countries in 2012 [2] [3]. The Zomato is expanding in the rapid rate but due to fierce competition, marketing strategies and providing perks to the customer decreases the profit margin, but the loss is gradually reduced.

This paper is on the analysis of various issues of a food supply company Zomato as per the procedure of the research methodology of company analysis [4], [5]. Section 3 provides financial status of the company. Section 4 analyses the various results and findings found by the survey conducted. Section 5 analyses strengths, weaknesses, opportunities and threats faced by online food delivery service. Section 6 discusses various advancements implemented. Section 7 discusses various challenges faced by online food delivery service. Section 8 discusses various steps taken by Zomato to help customers, restaurant and delivery partners. Section 9 provides suggestions for the improvement in online food delivery industry. Section 10 contains the conclusion to paper.

\section{METHODOLOGY:}

This paper consists of Financial Analysis and Order Analysis of Zomato for which data are collected from blogs \& website of Zomato. Different journal articles, white-paper, websites have been referred for SWOT analysis, challenges and different initiatives by Zomato. The survey is conducted to analyze 
different aspects related to the Online food delivery service. Analyzed the data collected using the SPSS tools.

\section{FINANCIAL ANALYSIS OF ZOMATO:}

The financial statement of the Zomato gives information about the health of the company. The Zomato is not only expanding to different regions but growing financially. From Table 1 . The revenue produced is increasing drastically in 2x from FY18 [6]. Even though the cost and EBITDA Loss is increasing the difference between revenue and EBITDA Loss is gradually decreasing and financial status of the company is becoming healthier. The Zomato earns through services like online food delivery service, dining out, hyperpure and subscription plans. The major portion of revenue is generated through online food delivery service where it delivers food from restaurants to customers. Collect delivery charges from customer and commission from restaurants. Dining out service gives privilege to the customer to book $1+1$ or $2+2$ table in the preferred restaurant. The hyperpure is a business to business service where fresh ingredients are delivered to restaurants. Due to COVID-19 because of different preventive measures taken by the government, the revenue from dining out service is drastically reduced, but other services are recovering at a good rate.

Table 1: Financial Status of Zomato

\begin{tabular}{|c|c|c|}
\hline Financial Year & Revenue (\$ m) & EBITDA Loss (\$ m) \\
\hline FY19 & 192 & 277 \\
\hline FY20 & 394 & 293 \\
\hline Q1 FY21 & 41 & 12 \\
\hline
\end{tabular}

The online food delivery service is recovering since loosening of lockdown. From Fig. 1. The MidCOVID Report 2 by Zomato-analyzed order sizes with Pre-COVID, Mid-COVID, and found ordering for the group or family is increased since customers are with their families, while single order has been decreased [7]. The increase in the order size per delivery has the amount generated from delivery charges. As the lockdown loosens further, shifting back from virtual to physical presence in different institutions, industries ordering size, pattern will revert back to Pre-COVID period.

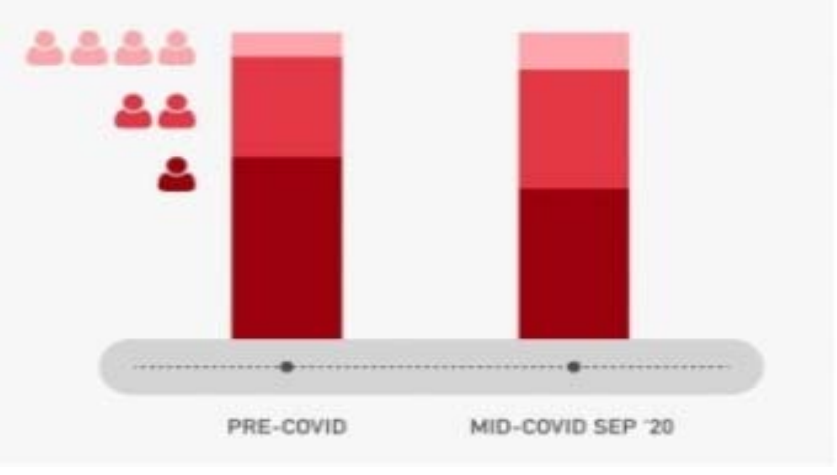

Fig. 1: Food Delivery India - Mid-COVID Report 2 - September 2020

\section{SURVEYAND ANALYSIS OF ONLINE FOOD INDUSTRY:}

The survey about different factors affecting the Online Food Delivery Service and individual perspective was conducted through online. The data are collected through Google forms and analyzed using Statistical Package for the Social Sciences (SPSS) tool.

Table 2. Apps Used to order Food shows the preference for different number of cases. Uber Eats was acquired by the Zomato, while Scootsy was recently acquired by Swiggy. The gap between Zomato and Swiggy is insignificant. The percentage of cases does not match $100 \%$ since the customers prefer different apps. Table 2. shows that customer is not loyal to one application and he/she is choosing 
International Journal of Case Studies in Business, IT, and Education (IJCSBE), ISSN: 2581-6942, Vol. 5, No. 1, January 2021

between the applications

Table 2: Apps Used to Order Food

\begin{tabular}{|c|c|c|}
\hline Apps Used to Order Food & \% & \% of Cases \\
\hline Zomato & $51.2 \%$ & $75.9 \%$ \\
\hline Swiggy & $41.9 \%$ & $62.1 \%$ \\
\hline Scootsy & $2.3 \%$ & $3.4 \%$ \\
\hline Uber Eats & $4.7 \%$ & $6.9 \%$ \\
\hline
\end{tabular}

Figure 2 shows the region-wise distribution of Online Food Delivery Service of individuals using online food delivery service/system. $75.9 \%$ and $24.1 \%$ individuals use online food delivery service in City/Metro region and Rural region. The number of users in City/Metro region is high compared to the rural region since restaurants and delivery partners are concentrated in City/Metro region.

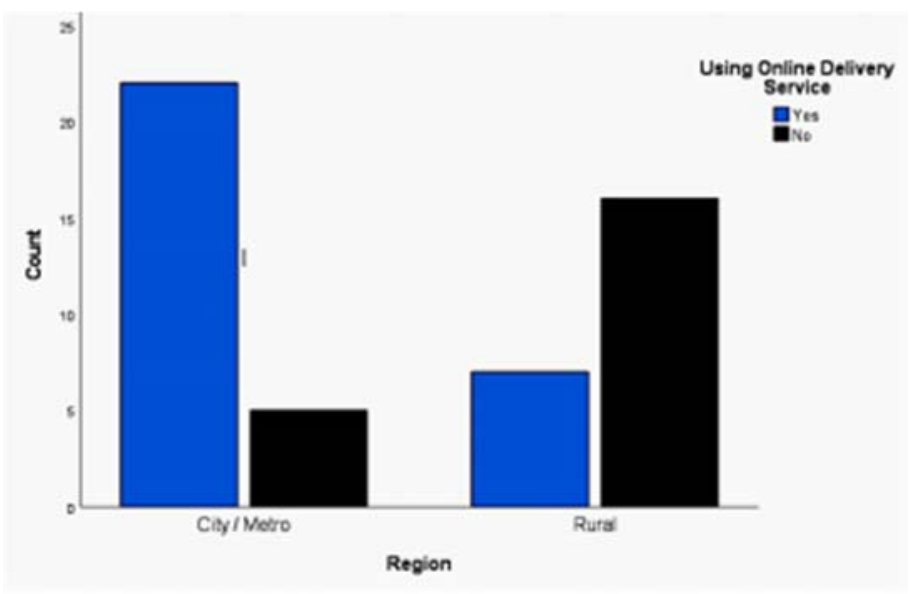

Fig. 2: Region-wise Distribution of Online Food Delivery Service

Figure 3 shows the preferred method for ordering food using online food delivery service through Food Delivery Mobile Apps/Food Delivery Website is high in $86.2 \%$ compared to that of ordering food through Phone Calls and Restaurant Website

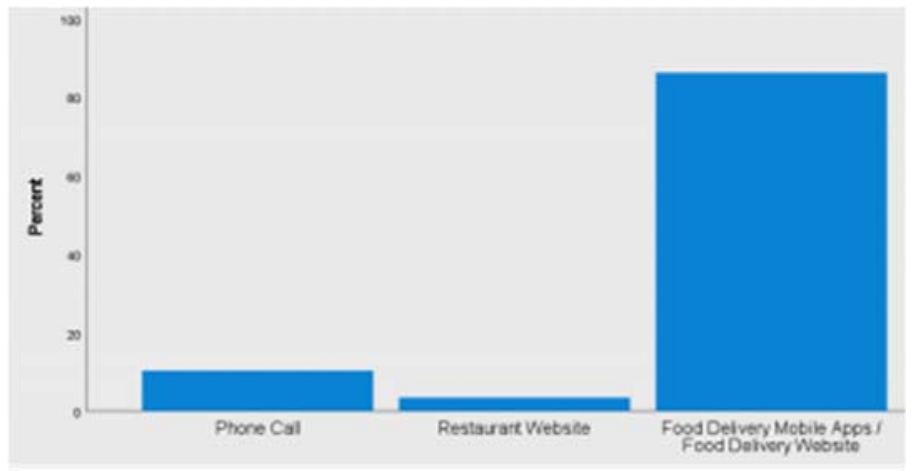

Fig. 3: The Preferred Method of Ordering Food.

Figure 4 shows the Order Per Month with average number of orders by the customer for the month. Most of the customers order $<3,3-6$ times a month. Individual ordering $<3$ or $3-6$ high since online food delivery service is mainly used during special events/occasion or Weekend. 


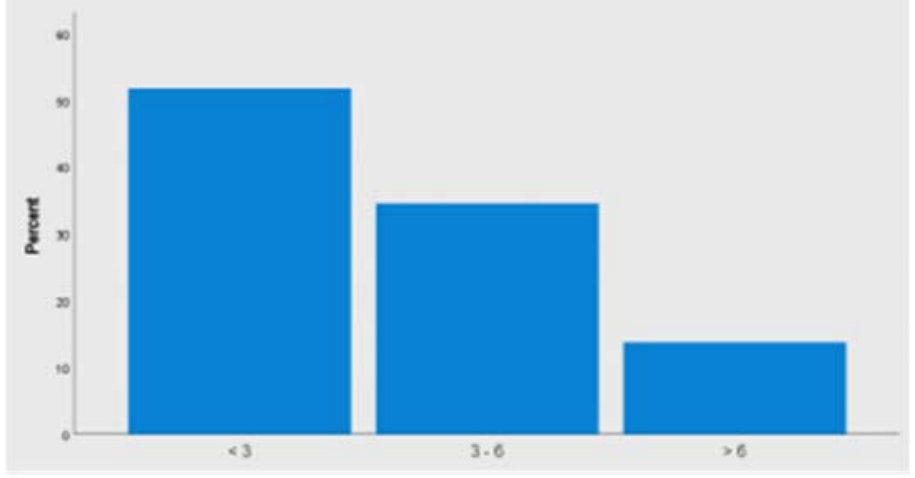

Fig. 4: Order Per Month

Figure 5 shows the money spent per month on average is similar to Figure 4 since more than $70 \%$ of people fall under $<500$ and $500-1000$. Less spending Is not only because less number of ordering per month but also because the restaurant that offers costly foods is not partnered with online food delivery service.

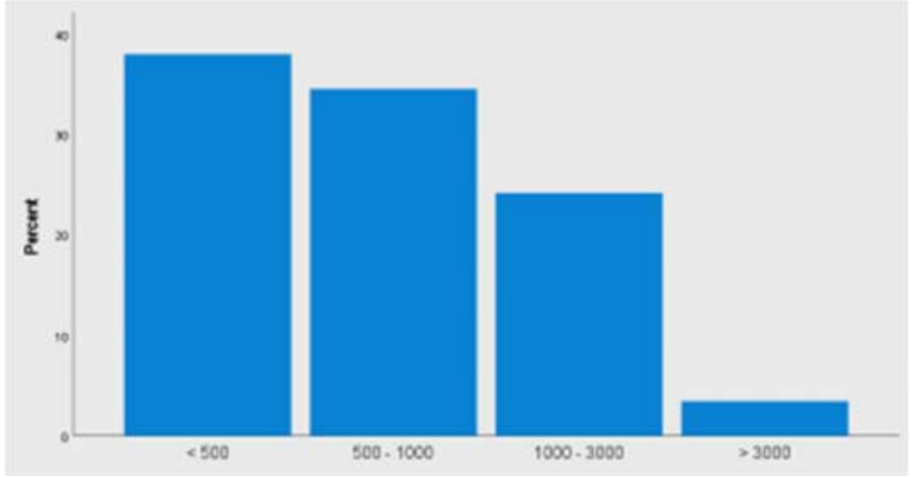

Fig. 5: Money Spent Per Month

Figure 6 shows the experience on food quality shows that $50 \%$ customers are not satisfied with food quality because of transportation, packaging, or delivery exceeding the time limit. The Zomato/online food delivery service should focus on food quality problem since it will not only create impact on loyalty and trust issues of customer, but also creates a hesitation with new customer.

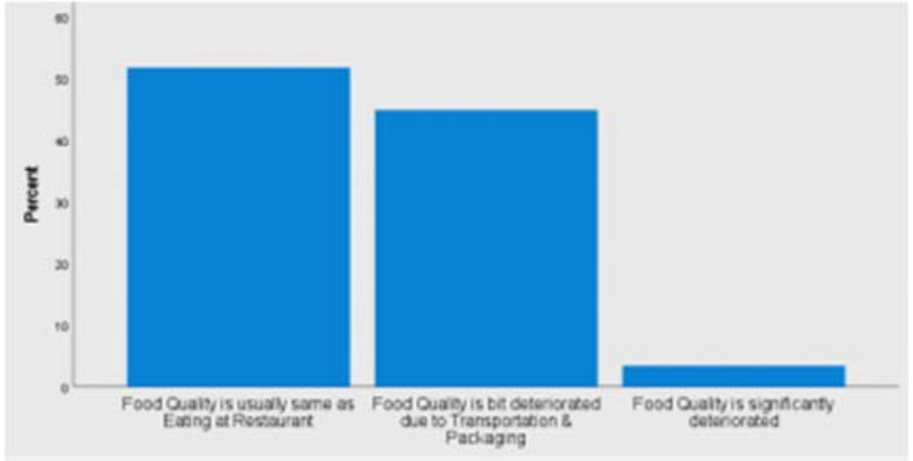

Fig. 6: Experience on Food Quality

Figure 7 shows subscription Plan most of the customers are not loyal to one brand or application. Whenever customer wants to order food he/she will compare one with another, which will not only create a fierce competition between competitors but also with customer loyalty. 


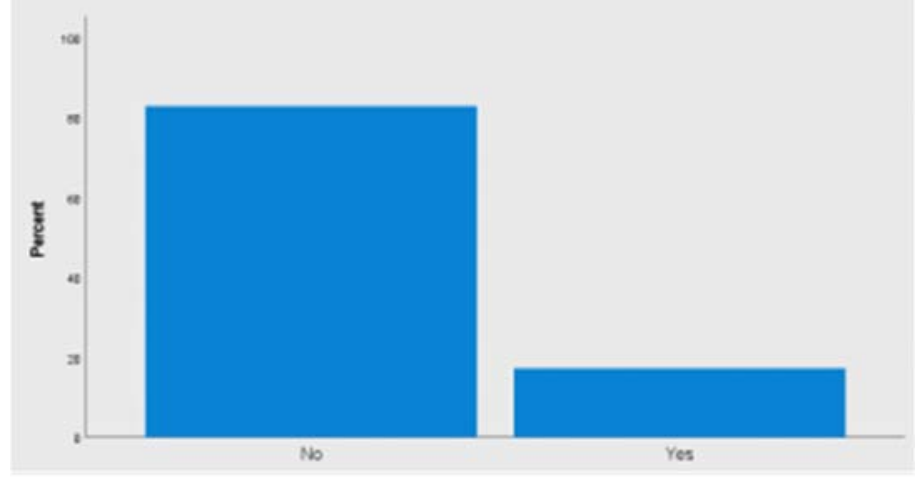

Fig. 7: Subscription Plan

Figure 8 Shows primary reason for ordering food shows $50 \%$ of customers order food because of convenience. So, it's good for food companies to focus on maintaining good quality, packaging, freshness and taste of food and timely delivery of order.

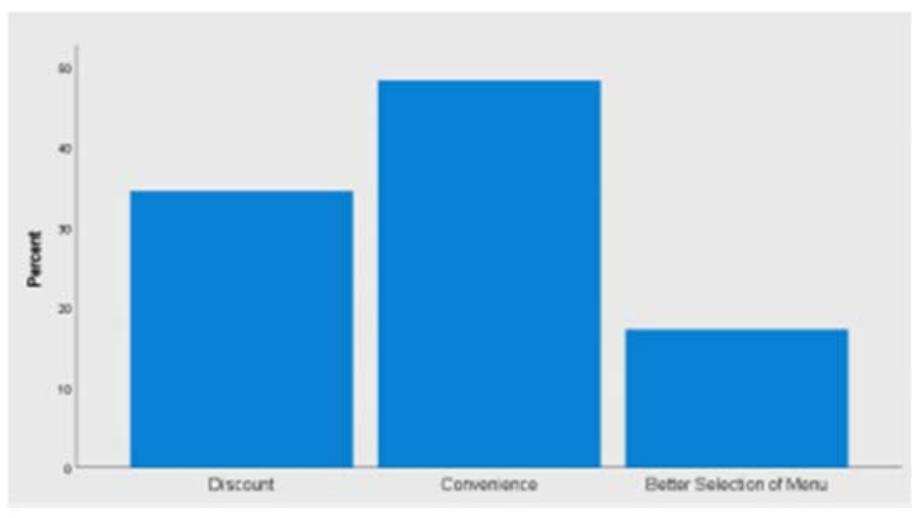

Fig. 8: Primary Reason for Ordering Food

Figure 9 shows preferring variety of Cuisines and more customers are willing to order food with various the cuisines or order food from different restaurant in the same delivery. When the customer is ordering food for the group or family-preferred cuisines, and taste varies from one another.

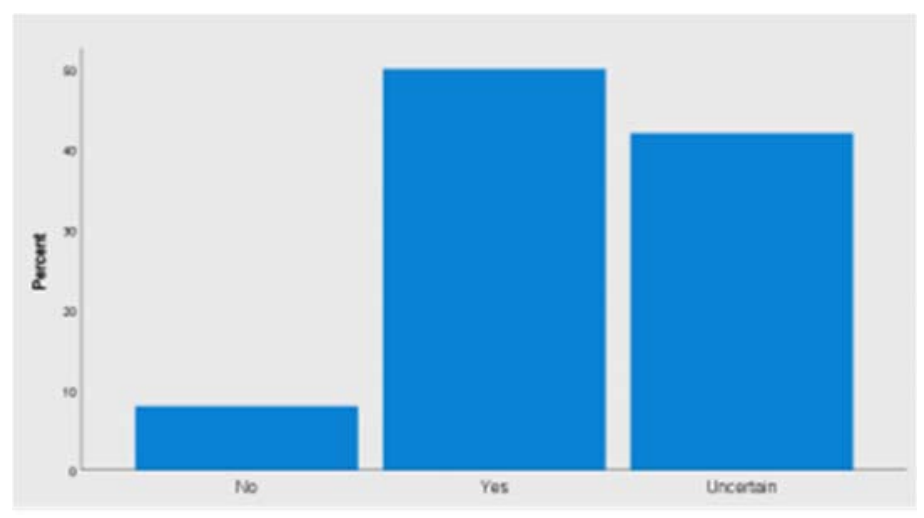

Fig. 9: Preferring Variety of Cuisines

Figure 10 shows that splitting of the bill need not be done since most individuals think it is not going to affect the industry/company/application as expected. 


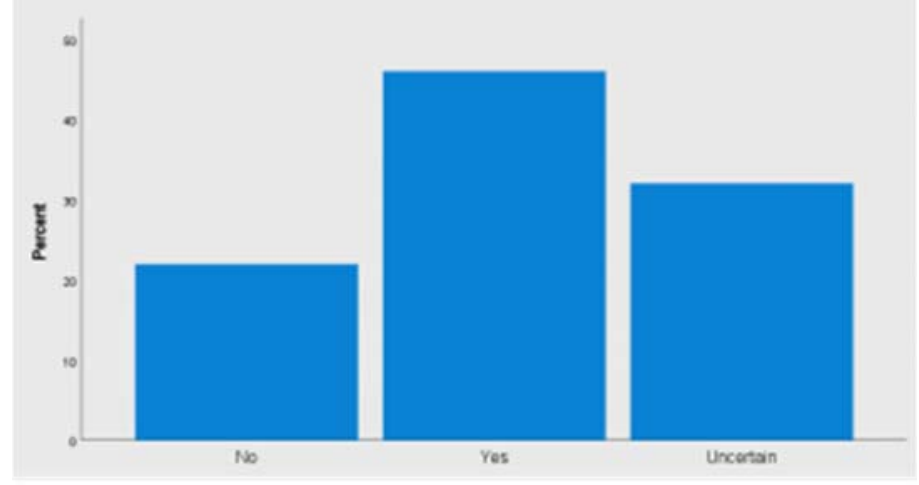

Fig. 10: Splitting of Bill

\section{SWOT ANALYIS:}

\subsection{Strengths}

Innovative Approach

Zomato has implemented many new ideas in every aspect and can take advantage of it. In COVID-19 period, the demand for online grocery delivery implemented it in certain major metro cities. Started contactless dinning encouraged cashless payment and food takeout services to prevent spreading of COVID-19 and provide confidence in restaurant partners, customers and delivery personals. Providing Hyperpure service in Bangaluru and Delhi where it supplies the 1200+ fresh hygienic ingredients and kitchen products to the restaurants in the preferred period. Providing period leaves for women's, which got huge public support [3].

\section{Global Presence}

Zomato is pioneer in online food delivery service/system in many countries, which has provided a major advantage in market share. Zomato is operating in 24 countries, $10000+$ cities with a team of $5000+$. 1.5 million+ listed restaurants provided various number of choices for the customer. Compared with its competitors it has huge customer base with 100 million+ monthly active customers [3].

\section{Acquisition}

Zomato easily established its stronghold in various countries, cities by acquiring 12 established wellknown startups, which not only reduced the fierce competition but also increased customer base by acquiring the resources and customer of acquired companies.

\section{Simple and User Friendly Interface}

The acquired startup belonging to technology helps in increased focus to the IT department. As the number of customers, listed restaurants, menu cards and reviews increase complexity increases and managing the system will be difficult. Zomato's design system Sushi, which is user centric, inclusive, simple and consistent. Increased user familiarity with the interface [3].

\subsection{Weakness \\ Security}

The company should maintain the security and integrity of the application to have the confidence of the customer. The Zomato uses the email address, phone number and location of the customer for providing better accessibility and service. The security of application was breached in 2015 and 2017 with loss of user information. The IT team is working mainly on this aspect to provide better security [8].

\section{Upgradation on Menu Cards and Growth at Rapid Rate}

The company is growing at a rapid rate with a huge number of listed restaurants. Zomato app consists of outdated menu cards, partial information, low-quality images about dishes, restaurants and other details that need to be updated [9]. The menu card and restaurant details of unlisted and blacklisted restaurants need to be removed from the app. Removing unwanted contents will decrease the burden on system/app and decrease the complexity of the system. Finding and upgradation of Menu cards, removing details related to blacklisted restaurants and its dishes becomes difficult rapid growth in company. 


\subsection{Opportunities}

Expand to Rural Areas \& Countries

The Zomato is expanding in the rapid rate, but it can only create influence only in certain countries. It has low influence in European countries. It can expand to other countries and expand its influence and customer base. Zomato along with other online food delivery systems is focusing on metro, city, semiurban and urban regions, since most of the orders and listed restaurants belong to these areas. The food delivery service is not provided in rural regions because of logistical issues [10], distance from the restaurant to the customer and unlisted restaurant in rural areas. The focus on rural areas will open completely new markets to online food delivery system/services [11] [12].

Increasing Number of smartphone Users

The online food service of Zomato is provided by website and application. The individuals below the age of 35 and students are the main customer base. The increase in penetration of internet increases the customer base. The importance needs to be provided to people not using the particular application to order, which will increase customer base.

\subsection{Threats}

\section{Competitors}

The market of online food delivery service/system remains unexplored and different companies are trying to gain the loyalty or trust of customer. Due to which there is an intense competition between competitors like Food Panda, Yelp, Beer Cafe, Eat, Swiggy, Dominos, Pizza Hut, Scootsy, Dunzo, etc [9] [13] [14]. Aggressive market strategies are created which is making companies to set low profit margin or loss.

\section{Google Services}

Zomato not only provides services such as food delivery and recommendations, navigation, dine out, menu cards, which are also provided by Google services. Google services provide details of different restaurants according to your location. Google services redirect customer/user to restaurants website or any online food delivery service/system where similar services are provided [8].

\section{Business Models}

Being the pioneer in the online food delivery service number of market strategies, business models were created by Zomato. Zomato's competitors are easily replicating strategies, business models used by Zomato and giving the intense competition.

\section{TECHNOLOGY:}

\subsection{Automation of Services}

The application is updated periodically to new lightweight framework, which is reducing the burden on the system. The Sushi system has made the system interface simpler and user friendly [15]. In 2019 technical improvement in the interface across functionality and services, the application greatly reduced the queries, redundant data, which resulted in $10 \%$ of the workforce [16] [17].

\subsection{Change in Reviewing System}

Zomato provides both online food delivery service and dining out service. The quality of the service, taste and freshness of the food provided vary for dining out and online food service. The single review system created ambiguity and wrong information since the review provided intended to other services. The updated system provided separate reviewing system for dining out and delivery service, which rated services without any ambiguity. The reviewing system of services is made identifiable because of colors [18].

\subsection{Detecting Suspicious Activity}

The restaurants with repeated patterns of solicitation, or trying to alter/influence comments or reviews of users are identified. The banner is added on the listings of the restaurants with suspicious activity, warning customers regarding it [18].

\section{CHALLENGES:}

\section{Customer Loyalty:}

The main need of any service industry is to provide the service to more customers, which will eventually increase the market share. The online delivery system/service works as customer-centric. Most of the customers do unstick to one particular application and to maintain a good number of customer base 
incentives, freebies and exclusive deals are provided. The customer is comparing all the aspects from different service providers, the customer loyalty keeps on changing depending on the different incentives provided [19].

\section{Market Prices:}

As the market grows so does the competition with different service provider. To attract more customers, companies are trying to provide good service, and food at low attractive price. Since price is continuously fluctuating, market price is unpredictable due to competition maintaining standard market price is difficult. The small players cannot cope with competitions, while big players get affected by loss they can rely on other sources to make up for loss. Providing incentives, freebies and exclusive deals will create extra burden [19] [20].

\section{Food Quality:}

The main concern for online food delivery system is quality and taste of the food. The food delivered to home and food in the restaurant will have completely different taste and quality. As the time taken for the delivery of food increases freshness, taste and quality decreases [21]. The presentation of food on the plate will miss due to packaging, rough handling of it in the delivery process. The customer order the same food from different restaurant due to special services offered. The taste, quality of food will be different from one restaurant to another [22] [23].

\section{Unreliable Delivery/Logistics:}

The online food delivery service/system should keep track of every information and analyze them to create an area of interest, allocating more vehicles and personal to high order concentrated areas and less personal to other areas, effective route creation for easy and fast delivery from restaurant to customers. Most of restaurants and delivery personals are unable to cope with the high number of orders during peak hours due to which quality, taste is deteriorated because of late delivery. The location service to be embedded in the system so that customer can easily located and can decrease the canceling of order, unable to provide timely delivery [24].

\section{INITIATIVE IN COVID-19 :}

In Mid COVID-19 to decrease the loss incurred itself and its delivery, restaurant partners due to the following lockdown rules. In Lockdowm period, $60 \%-70 \%$ of orders were reduced. Zomato understood the need of delivery of grocery, and it started online delivery of grocery in $80+$ cities. It also partnered with Grofers for delivery. Grocery delivery not only reduced the financial burden on company but also competed with JioMart and BigBasket [25].

\section{For Customers:}

- To remove the fear of getting transmitted with virus contactless delivery, where delivery personal drop delivery at a particular location, or in front of a door started.

- Face masks were distributed to customers and its partners

- Completely disabled cash on delivery and encouraged digital payment to reduce contact.

- Started grocery delivery to deliver groceries.

- The subscription plan Zomato Gold was extended [26].

For Delivery Partners:

- Donated money through Rider Relief Fund to the delivery personals since their earnings dropped with decrease in online food delivery

- Delivery Partner Insurance Plan helped delivery personals by covering hospitalization charges, and lost earning if they infected by COVID-19 [26].

For Restaurant Partners \& Workers:

- The Zomato Gold Support Fund helped the restaurant personal where annual subscription plan money was provided to them.

- Takeaway not only allowed customers to directly collect food from restaurants but also zero commissioned. Which reduced burden of customer and restaurants [26].

\section{RECOMMENDATIONS:}

The application must be high responsiveness, friendliness to handle unpredictable cases like unable to 
deliver food on time, wrong delivery etc. Timely delivery will increase the likeness toward the application since most complaints are related to it. The Zomato/online food delivery service does not have a strong base in the rural region because of a lack of delivery service and restaurant partners. Zomato can target college students in these areas since students spend more time in social media, in the period of developing buying/eating habits, limited mobility. The Zomato has a separate review system for online food delivery service and dine out but it should also provide a separate review system for delivery service since they influence one another. The actions can be easily implemented in the respective area. Provision to order food from different types of cuisines, and restaurant must be provided which will increase options to customers. Providing offers will increase the financial burden on company and not help in gaining customer loyalty, instead removing delivery charges can gain trust and more popularity with customers.

\section{CONCLUSION:}

The online delivery services are progressing at a rapid rate. Even though there has been a slowdown in the market due to customer buying habit is influenced by fear of spreading COVID-19 and implementation of Lockdown. After loosening of lockdown hotel-related industry in growing back, we can see increase in demand for online food delivery service. Zomato has taken lot of steps to come out of the crisis of COVID-19 and initiatives to help its partners. From the conducted survey decrease in the ordering can be seen, but as the time progresses, it is expected to grow back. From the survey, it can be noticed that customers are not loyal to one service provider. The zomato should expand itself to rural areas since lot of customers are available. The quality of food and logistical issues should be solved so food can be delivered on time.

\section{REFERENCES:}

[1] Gupta, M. (2019). A Study on Impact of Online Food delivery app on Restaurant Business special reference to zomato and swiggy. International Journal of Research and Analytical Reviews, 6(1), 889-893.

[2] Raina, A., Rana, V. S., \& Thakur, A. Si. (2018). Popularity of Online Food Ordering and Delivery Services- a Comparative Study Between Zomato, Swiggy and Uber Eats in Ludhiana. International Journal of Management, Technology and Engineering, 8(3), 350-355.

[3] Panigrahi, A., Saha, A., Shrinet, A., Nauityal, M., \& Gaur, V. (2020). A case study on Zomato The online Foodking of India. Journal of Management Research and Analysis, 7(1), 25-33.

[4] Aithal, P. S. (2017). Company Analysis-The Beginning Step for Scholarly Research. International Journal of Case Studies in Business, IT and Education (IJCSBE), 1(1), 1-18.

[5] Aithal, P. S. (2017). An effective method of developing business case studies based on company analysis. International Journal of Engineering Research and Modern Education (IJERME), 2(1), 16-27.

[6] Goyal, D. (2020). Zomato Mid COVID-19 Performance Report. In Zomato Pvt Ltd. Retrieved on January 10, 2021 from https://www.zomato.com/blog/mid-covid-report-2

[7] Goyal, D. (2020). Food Delivery India - Mid-COVID Report 2 September 2020. In Zomato Pvt Ltd. (Issue September). Retrieved on January 11, 2021 from https://www.zomato.com/blog/mid-covidreport-2

[8] Bhasin, H. (2018). SWOT analysis of Zomato - Zomato SWOT. Marketing91. Retrieved on December 28, 2020 from https://www.marketing91.com/swot-analysis-of-zomato/

[9] All Answers Ltd. (2018). SWOT Analysis of Zomato | Business Teacher. Retrieved on January 20, 2021 from https://businessteacher.org/swot/zomato-swot.php

[10] Gawande, N., Pachaghare, G., \& Deshmukh, A. (2019). A Study of Customer Perception about Online Food Ordering Services in Amravati City. International Journal of Latest Technology in Engineering, Management \& Applied Science (IJLTEMAS), 8(4), 114-116.

[11] Thamaraiselvan, N., Jayadevan, G. R., \& Chandrasekar, K. S. (2019). Digital food delivery apps 
revolutionizing food products marketing in India. International Journal of Recent Technology and Engineering, 8(2S6), 662-665.

[12] Mohanapriya, M. A., Geetha, M. P., \& Prasathkumar, M. A. (2020). A Comparative Study on Customer Preference Towards Online Food Ordering System and Restaurant with Special Reference to Coimbatore District. International Journal of Disaster Recovery and Business Continuity, 11(1), 1326-1332.

[13] Jagannath Mane, P. (2020). Study of Online Food Delivery App like Zomato \& Swiggy and their effect on Casual Dining. International Journal of Scientific Research and Engineering Development, 10(10), 681-684.

[14] Das, J. (2018). Consumer Perception Towards "Online Food Ordering and Delivery Services": An Empirical Study. Journal of Management (JOM), 5(5), 155-163.

[15] Verma, V. (2019). Zomato's new Sushi Design System. Zomato Pvt Ltd. Retrieved on 7 January, 2021 from https://www.zomato.com/blog/sushi

[16] Keeble, M., Adams, J., Sacks, G., Vanderlee, L., White, C. M., Hammond, D., \& Burgoine, T. (2020). Use of online food delivery services to order food prepared away-from-home and associated sociodemographic characteristics: A cross-sectional, multi-country analysis. International Journal of Environmental Research and Public Health, 17(14), 1-17.

[17] Tandon, S. (2019). Zomato lays off 540 employees across customer support teams. Live Mint. Retrieved on 15 January, 2021 from https://www.livemint.com/companies/news/zomato-lays-off540-employees-across-customer-support-teams-1567852078631.html

[18] Jain, R. (2020). Introducing our new ratings system. Zomato Pvt Ltd. Retrieved on 15 December, 2020 from https://www.zomato.com/blog/new-ratings

[19] The Restaurant Times. (2021). 7 Challenges Faced by Food Delivery Services and How to Address Them. Retrieved on 10 December, 2020 from https://www.posist.com/restaurant-times/restrogyaan/food-delivery-challenges.html

[20] Vikranth, K., \& Krishna Prasad, K. (2020). The Sustained Improvements in E-commerce Business through Big Data and Data Analytics of Wal-Mart Company. International Journal of Case Studies in Business, IT, and Education (IJCSBE), 4(2), 28-39.

[21] Pradeep, M. D. \& D’Mello, Laveena (2020). Literature Review on Social Opportunities for the Solar Cold Chain System in India-An Exploratory Study. International Journal of Applied Engineering and Management Letters (IJAEML), 4(1), 131-141.

[22] Das, S., \& Ghose, D. (2019). Influence of online food delivery apps on the operations of the restaurant business. International Journal of Scientific and Technology Research, 8(12), 13721377.

[23] Gupta, A., Gupta, A., Singh, S., \& Surana, V. (2019). Factors Affecting Adoption of Food Delivery Apps. International Journal of Advanced Research, 7(10), 587-599.

[24] Mishra, C. (2020). The Major Challenges Faced by Online Food Delivery Businesses. Medium. Retrieved on 10 December, 2020 from https://chiragm984.medium.com/the-major-challengesfaced-by-online-food-delivery-businesses-94cce55fd037

[25] Tandon, S., \& Bhalla, T. (2020). Zomato scales back grocery as food delivery recovers. Live Mint. Retrieved on 13 January, 2021 from https://www.livemint.com/companies/start-ups/zomato-refocuses-on-food-delivery-as-orders-improve-11591362119072.html

[26] Deepinder, G. (2020). Summary of all of Zomato's COVID-19 related initiatives. Zomato Pvt. Ltd. Retrieved on 6 December, 2020 from https://www.zomato.com/blog/covid-19-initiatives

$* * * * * * * * * * * * *$ 